\title{
Whole-brain Radiation Therapy for Intracranial Metastases as Initial or Late Treatment
}

\author{
HISATO HIRANUMA ${ }^{1}$, NAOYA ISHIBASHI ${ }^{2}$, TOSHIYA MAEBAYASHI ${ }^{2}$, TAKUYA AIZAWA ${ }^{2}$, \\ MASAKUNI SAKAGUCHI ${ }^{2}$, MASAHARU HATA ${ }^{3}$, MASAHIRO OKADA ${ }^{2}$ and YASUHIRO GON ${ }^{1}$ \\ ${ }^{1}$ Division of Respiratory Medicine, Department of Internal Medicine, Nihon University School of Medicine, Tokyo, Japan; \\ ${ }^{2}$ Department of Radiology, Nihon University School of Medicine, Tokyo, Japan; \\ ${ }^{3}$ Department of Radiation Oncology, Yokohama City University Graduate School of Medicine, Kanagawa, Japan
}

\begin{abstract}
Background/Aim: We examined the difference between whole-brain radiation therapy (WBRT) for intracranial metastases (IM) from lung cancer as an initial and as a late treatment affecting overall survival (OS). Patients and Methods: Thirty-three patients who presented with IM at initial examination who received WBRT as the initial treatment (initial WBRT group) and 47 patients without IM or with asymptomatic IM at initial examination who received WBRT after systemic therapy, between January 2014 and December 2020, were retrospectively analyzed. Patients' OS after WBRT were compared. Results: Median OS was significantly longer in patients treated with systemic anticancer therapy after WBRT than in patients who were not (176 vs. 47 days, respectively; $p<0.001)$, and systemic anticancer therapy after WBRT was a significant prognostic factor $(p<0.001)$. Conclusion: Treatment with systemic anticancer therapy after WBRT may prolong the survival of patients who present with IM at initial examination.
\end{abstract}

Lunq cancer is likely to cause brain metastases (BM). In non-small-cell lung cancer (NSCLC), BM is reported to occur in $50 \%$ of patients during the disease course and in 16$30 \%$ after definitive radiation therapy $(1,2)$. In small-cell lung cancer, BM is detected in $10-14 \%$ of patients at initial examination and occurs in 59\% after definitive radiation therapy $(3,4)$. The National Comprehensive Cancer Network guidelines recommend whole-brain radiation therapy

This article is freely accessible online.

Correspondence to: Naoya Ishibashi, MD, Ph.D., Department of Radiology, Nihon University School of Medicine, 30-1 Oyaguchi Kami-cho, Itabashi-ku, Tokyo 173-8610, Japan. Tel: +81 339728111, Fax: +81 339582454, e-mail: ishibashi.naoya@nihon-u.ac.jp

Key Words: Whole-brain radiation therapy, intracranial metastases, initial treatment, lung cancer.
(WBRT) for patients with four or more BM from NSCLC and for patients with BM from small-cell lung cancer $(5,6)$. Regarding patients with 1-4 BM, several randomized controlled trials reported that the addition of WBRT to stereotactic radiosurgery significantly reduced subsequent intracranial recurrence but did not improve overall survival (OS) (7-9). To determine the prognosis of BM, recursive partition analysis based on the performance status and age of patients receiving WBRT and the presence or absence of controlled primary tumors and extracranial metastases was previously proposed (10). Subsequently, lung graded prognostic assessment was developed by incorporating the number of BMs in patients receiving WBRT or other therapies for BM from lung cancer (11). In recent years, a graded prognostic assessment that incorporates gene mutations or rearrangements has been performed in patients with NSCLC who received WBRT and other therapies (12). When long-term survival is expected based on this assessment, an increase in the total dose of WBRT is also considered. We encountered patients with lung cancer presenting with four or more intracranial metastases (IMs; including meningeal dissemination) at initial examination who received WBRT as their initial treatment followed by systemic anticancer therapy and who achieved long-term survival. To our knowledge, there are only two previous reports on the timing of WBRT and OS. Both indicated that administration of chemotherapy before WBRT did not affect OS in patients who presented with IMs at initial examination of NSCLC $(13,14)$. In the present study, we compared OS between the initial WBRT group, which consisted of patients with IMs at the initial examination who received upfront WBRT (initial WBRT group), and patients treated with WBRT after systemic anticancer therapy (late WBRT group). The latter was composed of patients without IM at the initial examination who received systemic anticancer therapy followed by WBRT after the appearance of IMs, and patients with asymptomatic IMs at the initial examination who received systemic anticancer therapy followed by WBRT 
Table I. Characteristics of study patients.

\begin{tabular}{|c|c|c|c|c|}
\hline Characteristic & Subgroup & Initial WBRT & Late WBRT & $p$-Value \\
\hline Patients & Total & $\mathrm{n}=33$ & $\mathrm{n}=47$ & \multirow{3}{*}{0.406} \\
\hline \multirow{2}{*}{ Gender } & Male & $28(84.8 \%)$ & $35(74.5 \%)$ & \\
\hline & Female & $5(15.2 \%)$ & $12(25.5 \%)$ & \\
\hline Age at WBRT, years & Median (range) & $69(49-83)$ & $70(29-85)$ & \multirow[t]{12}{*}{0.651} \\
\hline \multirow[t]{11}{*}{ Primary histological type, n (\%) } & Adenocarcinoma & $16(48.5 \%)$ & $16(34.0 \%)$ & \\
\hline & With gene mutation/rearrangement, $\mathrm{n}$ & & & \\
\hline & Yes & 5 & 3 & \\
\hline & No & 10 & 12 & \\
\hline & Unknown & 1 & 1 & \\
\hline & Adenosquamous carcinoma & $0(0 \%)$ & $1(2.1 \%)$ & \\
\hline & Small-cell carcinoma & $10(30.3 \%)$ & $24(51.1 \%)$ & \\
\hline & Squamous cell carcinoma & $1(3.0 \%)$ & $4(8.5 \%)$ & \\
\hline & Large-cell neuroendocrine carcinoma & $2(6.1 \%)$ & $0(0 \%)$ & \\
\hline & Carcinoma only & $1(3.0 \%)$ & $0(0 \%)$ & \\
\hline & Lung tumor only & $3(9.1 \%)$ & $2(4.3 \%)$ & \\
\hline \multirow[t]{2}{*}{ IM at initial diagnosis, $\mathrm{n}(\%)$} & Yes & $33(100 \%)$ & $11(23.4 \%)$ & \\
\hline & No & $0(0 \%)$ & $36(76.6 \%)$ & \\
\hline \multirow[t]{3}{*}{ ECOG PS at WBRT, n (\%) } & $0-1$ & $16(48.5 \%)$ & $17(36.2 \%)$ & \multirow[t]{3}{*}{0.357} \\
\hline & 2 & $15(45.4 \%)$ & $30(63.8 \%)$ & \\
\hline & 3 & $2(6.1 \%)$ & $0(0 \%)$ & \\
\hline \multirow[t]{2}{*}{ Symptom at WBRT, n (\%) } & Yes & $12(36.4 \%)$ & $17(36.2 \%)$ & \multirow[t]{2}{*}{$>0.99$} \\
\hline & No & $21(63.6 \%)$ & $30(63.8 \%)$ & \\
\hline \multirow[t]{3}{*}{ No. of IMs at WBRT, n (\%) } & 1 & $0(0 \%)$ & $5(10.6 \%)$ & \\
\hline & $2-3$ & $9(27.3 \%)$ & $7(14.9 \%)$ & \\
\hline & $\geq 4$ & $24(72.7 \%)$ & $35(74.5 \%)$ & $>0.99$ \\
\hline \multirow{2}{*}{$\begin{array}{l}\text { Extracranial metastatic disease } \\
\text { at WBRT, } \mathrm{n}(\%)\end{array}$} & Yes & $24(72.7 \%)$ & $34(72.3 \%)$ & \multirow{2}{*}{$>0.99$} \\
\hline & No & $9(27.3 \%)$ & $13(27.7 \%)$ & \\
\hline \multirow[t]{4}{*}{ RT regimen, $\mathrm{n}(\%)$} & $20 \mathrm{~Gy} / 5 \mathrm{fr}$ & $2(6.1 \%)$ & $1(2.1 \%)$ & \multirow{4}{*}{$>0.99$} \\
\hline & $30 \mathrm{~Gy} / 10 \mathrm{fr}$ & $27(81.8 \%)$ & $38(80.6 \%)$ & \\
\hline & $37.5 \mathrm{~Gy} / 15 \mathrm{fr}$ & $3(9.1 \%)$ & $4(8.5 \%)$ & \\
\hline & $40 \mathrm{~Gy} / 20 \mathrm{fr}$ & $1(3.0 \%)$ & $4(8.5 \%)$ & \\
\hline \multirow{2}{*}{$\begin{array}{l}\text { Systemic anticancer therapy } \\
\text { with WBRT, } \mathrm{n}(\%)\end{array}$} & Yes & $8(24.2 \%)$ & $4(8.5 \%)$ & \multirow[t]{2}{*}{0.064} \\
\hline & No & $25(75.8 \%)$ & $43(91.5 \%)$ & \\
\hline \multirow{3}{*}{$\begin{array}{l}\text { Systemic anticancer therapy } \\
\text { after WBRT, n (\%) }\end{array}$} & Yes & $23(69.7 \%)$ & $22(46.8 \%)$ & \multirow[t]{3}{*}{0.066} \\
\hline & TKI & 3 & 1 & \\
\hline & No & $10(30.3 \%)$ & $25(53.2 \%)$ & \\
\hline
\end{tabular}

ECOG PS: Eastern Cooperative Oncology Group performance status; IM: intracranial metastasis; RT: radiotherapy; TKI: tyrosine kinase inhibitor; WBRT: whole-brain radiation therapy.

after exacerbation of IMs. We focused on the provision of systemic anticancer therapy after WBRT and wanted to recommend the ideal WBRT schedule in this study.

\section{Patients and Methods}

We retrospectively examined 80 patients with lung cancer as the primary tumor and IM detected by brain magnetic resonance imaging or computed tomography who received WBRT between January 2014 and December 2020. We divided the patients into two groups: i) The initial WBRT group, including patients with IM at their initial examination who received WBRT as initial treatment; and ii) the late WBRT group, including patients without IM at the initial examination who received systemic anticancer therapy followed by WBRT after the appearance of IMs, and patients with asymptomatic IMs at the initial examination who received systemic anticancer therapy followed by WBRT after exacerbation of IMs. We included patients who received systemic anticancer therapy combined with radiation therapy for the primary lesion but excluded patients whose primary lesion was surgically resected.

This study was approved by our Institutional Review Board (approval number: RK-210209-4) and informed consent was obtained from all patients. We have read the Declaration of Helsinki and conformed with its principles in this investigation.

Statistical analyses. SPSS version 21.0 (IBM, Armonk, NY, USA) was used for the statistical analysis. The patients' characteristics in the initial and late WBRT groups were compared using Fisher's exact test. The study endpoint was OS and OS was measured from the completion of WBRT. Differences in OS after the completion of WBRT between subgroups of patients were analyzed using the univariate log-rank test and multivariate Cox proportional hazard model for the following patient characteristics: Sex, age $(<$ median $v s$. 
Table II. Univariate and multivariate analyses of predictors of overall survival after whole-brain radiation therapy (WBRT).

\begin{tabular}{|c|c|c|c|c|}
\hline \multirow[b]{2}{*}{ Prognostic factor } & & \multirow{2}{*}{$\frac{\text { Univariate analysis }}{p \text {-Value }}$} & \multicolumn{2}{|c|}{ Multivariate analysis } \\
\hline & & & HR (95\% CI) & $p$-Value \\
\hline Age at WBRT & $<70$ vs. $\geq 70$ Years & 0.470 & $1.031(0.637-1.670)$ & 0.901 \\
\hline Gender & Male $v s$. Female & 0.154 & $1.780(0.935-3.387)$ & 0.079 \\
\hline ECOG PS at WBRT & $0-1$ vs. 2-3 & 0.036 & $1.341(0.741-2.426)$ & 0.333 \\
\hline Symptoms at WBRT & Yes $v s$. No & 0.114 & $1.301(0.720-2.349)$ & 0.383 \\
\hline No. of intracranial metastasis at WBRT & $1-3 v s . \geq 4$ & 0.950 & $1.116(0.610-2.040)$ & 0.722 \\
\hline Extracranial metastatic disease at WBRT & Yes $v s$. No & 0.985 & $0.913(0.503-1.658)$ & 0.764 \\
\hline WBRT arm & Initial $v s$. Late & 0.011 & $0.684(0.387-1.207)$ & 0.190 \\
\hline Systemic anticancer therapy after WBRT & Yes vs. No & 0.000001 & $0.369(0.218-0.626)$ & 0.000215 \\
\hline
\end{tabular}

CI: Confidence interval; ECOG PS: Eastern Cooperative Oncology Group performance status. Statistically significant $p$-values are shown in bold.

$\geq$ median), Eastern Cooperative Oncology Group (ECOG) performance status $(0-1 v s . \geq 2)$, symptoms (yes $v s$. no), number of IMs $(1-3 v s . \geq 4)$, extracranial metastatic disease (yes vs. no), WBRT group (initial WBRT $v s$. late WBRT), and administration of systemic anticancer therapy after WBRT (yes $v s$. no). Differences with $p$-values of less than 0.05 were considered to denote statistical significance.

\section{Results}

Patient characteristics. The initial WBRT group consisted of 33 patients, and the late WBRT group of 47 patients. The clinical data of all 80 patients are summarized in Table I. There were 28 men $(84.8 \%)$ and five women $(15.2 \%)$ in the initial WBRT group and 35 men $(74.5 \%)$ and 12 women $(25.5 \%)$ in the late WBRT group. Both groups were similar in terms of sex distribution. The median age at the time of all WBRT was 70 years, and the proportions of patients of median age or greater were similar in both groups. The most common primary histological type was adenocarcinoma (16 patients, $48.5 \%)$ in the initial WBRT group and small-cell carcinoma (24 patients, $51.1 \%$ ) in the late WBRT group. In adenocarcinomas, gene mutations (epidermal growth factor receptor) or rearrangements (anaplastic lymphoma kinase) were detected in only five patients in the initial WBRT group and three patients in the late WBRT group. These patients had received a tyrosine kinase inhibitor (TKI). The ECOG performance status at the time of WBRT was 3 or less in both groups, which were similar in terms of their performance status. At the time of WBRT, symptoms associated with IM were observed in 12 patients $(36.4 \%)$ in the initial WBRT group and 17 patients $(36.2 \%)$ in the late WBRT group. The proportions of patients with symptomatic IM were similar in both groups. The number of IMs was defined as the number of masses, including leptomeningeal metastasis, detected on magnetic resonance imaging or computed tomography. The most common number of IMs was four or more, which was observed in 24 patients $(72.7 \%)$ in the initial WBRT group and 35 patients $(74.5 \%)$ in the late WBRT group. Both groups were similar in terms of the number of IM. Only five patients $(10.6 \%)$ in the late WBRT group had a single IM. In the initial WBRT group, only two patients received WBRT for residual lesions after resection of IMs. Extracranial metastasis at the time of WBRT was observed in 24 patients $(72.7 \%)$ in the initial WBRT group and 34 patients $(72.3 \%)$ in the late WBRT group. Both groups were similar in terms of the presence or absence of extracranial metastasis. In most of the patients ( $80 \%$ or more), WBRT was administered with a 4 $10 \mathrm{MV}$ linear accelerator, and the radiotherapy regimen was 30 Gy in 10 daily fractions. Both groups were treated in a similar manner. Concurrent systemic anticancer therapy with WBRT was defined as systemic anticancer therapy that was begun within 14 days before the initiation of WBRT. Eight patients $(24.2 \%)$ in the initial WBRT group and four patients $(8.5 \%)$ in the late WBRT group received this treatment. After WBRT, systemic anticancer therapy was administered to 23 patients $(69.7 \%)$ in the initial WBRT group and 22 patients $(46.8 \%)$ in the late WBRT group, and TKI was administered after WBRT to three and one patient, respectively. More patients in the initial WBRT group received systemic anticancer therapy with WBRT or after WBRT ( $p=0.064$ and $p=0.066$, respectively).

Overall survival. All patients were followed-up until death from primary disease. Table II lists the results of univariate and multivariate analyses for associations between patient characteristics and prognosis after WBRT. Figures 1 and 2 summarize the comparisons of OS after WBRT between the initial WBRT group and the late WBRT group, and between patients treated with and without systemic anticancer therapy after WBRT. Univariate analysis showed that the median OS in the group treated with systemic anticancer therapy after WBRT was significantly longer than that in the WBRT group that did not receive this subsequent treatment (176 vs. 47 days, respectively; $p<0.001)$. Multivariate analysis also identified administration of this treatment after WBRT as a 


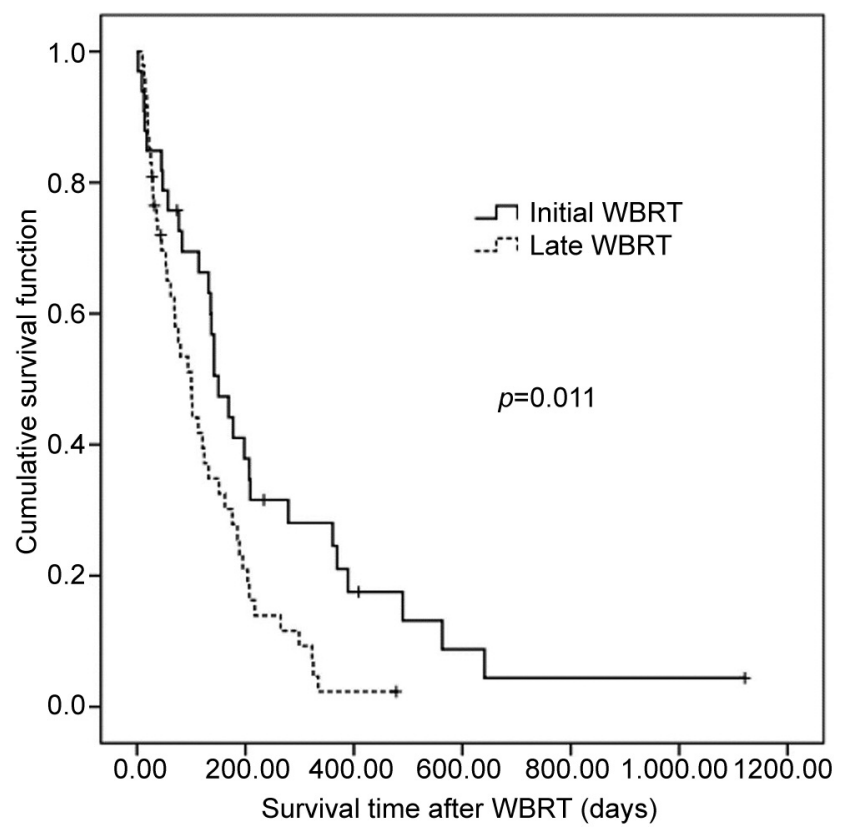

Figure 1. Kaplan-Meier survival curves of patients treated with initial or late whole-brain radiation therapy (WBRT). The difference between the two groups was statistically significant.

greatly significant prognostic factor $(p<0.001)$. Univariate analysis showed that OS was significantly longer in the initial WBRT group than in the late WBRT group $(p=0.011)$ but multivariate analysis did not identify initial treatment with WBRT as a significant prognostic factor. Univariate analysis showed that OS was significantly longer in patients with an ECOG performance status of $0-1$ at the time of WBRT than in those with an ECOG performance status of $\geq 2(p=0.036)$ but multivariate analysis did not identify ECOG performance status as a significant prognostic factor.

\section{Discussion}

The survival of patients with IM from lung cancer is poor, with recent reports indicating a median survival of approximately 7 months $(1,11,15)$. Stereotactic radiosurgery has been performed in patients with as few as 1-4 IMs, and the addition of WBRT is considered to reduce subsequent intracranial recurrence $(7,8,9)$. WBRT remains the standard treatment for patients with as many as four or more IMs (16, 17). However, the benefit of WBRT to prognosis is unknown. A recent randomized controlled trial of optimal supportive care including dexamethasone in combination with or without WBRT showed no significant difference in OS (18). The timing of WBRT varied in that trial, and the administration of systemic anticancer therapy before WBRT was also permitted. Only two randomized controlled trials

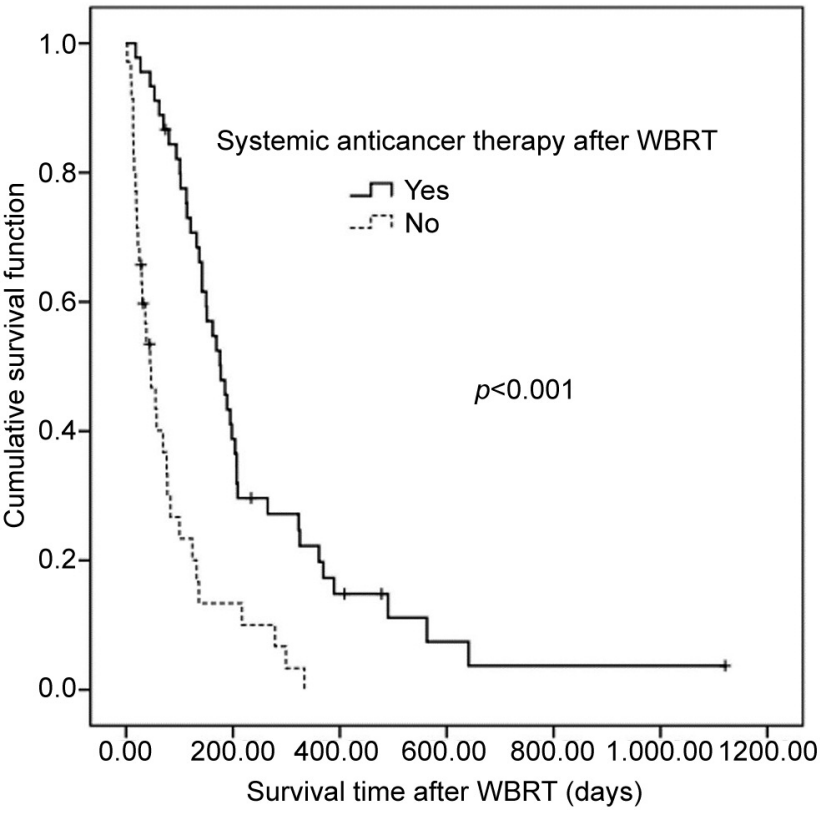

Figure 2. Kaplan-Meier survival curves of patients treated with and without systemic anticancer therapy after whole-brain radiation therapy (WBRT). The difference between the two groups was statistically significant.

on the timing of WBRT and prognosis have been reported, in which patients with BMs at the initial examination of NSCLC received chemotherapy before WBRT. Both trials showed that WBRT did not affect OS $(13,14)$.

In the present study, the timing of IM detection varied from initial examination to after systemic anticancer therapy. There was only one previous report on the timing of IM detection and OS, which indicated that OS was longer in patients with IM detected after the initial examination than in those with IM detected at presentation (15). This finding, which the results of the present study contradict, seemed to be because many patients with IM at presentation in that study did not receive chemotherapy.

In the present study, we compared the survival rates of the initial and late WBRT groups. Univariate analysis showed that OS was significantly longer in the initial WBRT group than in the late WBRT group, whereas multivariate analysis revealed that OS was significantly longer in the group receiving systemic anticancer therapy after WBRT. This suggests that administration of systemic anticancer therapy after WBRT was more effective in the initial WBRT group than in the late WBRT group.

In the group receiving systemic anticancer therapy after WBRT in the present study, the median OS was 176 days, which was longer than the 9.2 weeks in a group receiving optimal supportive care combined with WBRT in a previous report (18). This difference can be explained because that 
study included many patients with a poorer performance status compared with our study. The current standard regimen of WBRT is $30 \mathrm{~Gy}$ in 10 fractions or $20 \mathrm{~Gy}$ in five fractions because no significant difference in OS was shown in previous irradiation dose increment studies $(19,20)$. Although an accelerated regimen of 40 Gy in 20 fractions twice daily was also examined in recent years, OS did not differ between this regimen and a regimen of $20 \mathrm{~Gy}$ in five fractions (21, 22). The present study identified treatment with systemic anticancer therapy after WBRT as a markedly significant prognostic factor for the first time, while the WBRT regimen was $30 \mathrm{~Gy}$ in 10 fractions in most patients. In the future, rapid switching from WBRT to systemic anticancer therapy may prolong OS. In patients with WBRT as an initial treatment, prolongation of treatment duration with an increased total irradiation dose may not be necessary, but short-term irradiation may be beneficial. One limitation of the present study was that we were unable to evaluate neurological functions and intracranial recurrence after WBRT. This was attributed to the inclusion of more patients with an ECOG performance status of $\geq 2$ in the present study compared with previous reports of WBRT. Correct neurological and repeat imaging evaluation was difficult. Another limitation of this study was that, while recent reports have indicated that OS is improved by systemic anticancer therapy with TKI in patients with metastatic lung cancer in whom gene mutations or rearrangements are detected $(23,24)$, the present study included only eight patients who had gene mutations or rearrangements. In the future, we will accumulate data on patients receiving short-term WBRT as an initial treatment and the effect of gene mutations or rearrangements, and examine the association between these features and OS.

In patients with WBRT as an initial treatment, immediate induction of systemic anticancer therapy after WBRT may be beneficial in OS.

\section{Conflicts of Interest}

Drs. Hiranuma, Ishibashi, Maebayashi, Aizawa, Sakaguchi, Hata, Okada and Gon declare that they have no competing interests.

\section{Authors' Contributions}

$\mathrm{HH}$ and NI collected the patient data and treated the patients, and were major contributors to writing the article. MO interpreted the magnetic resonance imaging and computed tomography images. TM, TA, MS, MH and YG treated the patients. All Authors read and approved the final article.

\section{Acknowledgements}

The Authors thank H. Nikki March, Ph.D., from Edanz Group (https://en-author-services.edanzgroup.com/ac) for editing a draft of this article.

\section{References}

1 Dawe DE, Greenspoon JN and Ellis PM: Brain metastases in non-small-cell lung cancer. Clin Lung Cancer 15(4): 249-257, 2014. PMID: 24954227. DOI: 10.1016/j.cllc.2014.04.008

2 Perez CA, Pajak TF, Rubin P, Simpson JR, Mohiuddin M, Brady LW, Perez-Tamayo $\mathrm{R}$ and Rotman $\mathrm{M}$ : Long-term observations of the patterns of failure in patients with unresectable non-oat cell carcinoma of the lung treated with definitive radiotherapy. Report by the Radiation Therapy Oncology Group. Cancer 59(11): 1874-1881, 1987. PMID: 3032394. DOI: 10.1002/1097-0142(19870601)59:11<1874:: aid-cncr2820591106>3.0.co;2-z

3 Hirsch FR, Paulson OB, Hansen $\mathrm{HH}$ and Vraa-Jensen J: Intracranial metastases in small cell carcinoma of the lung: correlation of clinical and autopsy findings. Cancer 50(11): 2433-2437, 1982. PMID: 6182974. DOI: 10.1002/10970142(19821201)50:11<2433::aid-cncr2820501131>3.0.co;2-e

4 Aupérin A, Arriagada R, Pignon JP, Le Péchoux C, Gregor A, Stephens RJ, Kristjansen PE, Johnson BE, Ueoka H, Wagner H and Aisner J: Prophylactic cranial irradiation for patients with small-cell lung cancer in complete remission. Prophylactic Cranial Irradiation Overview Collaborative Group. N Engl J Med 341(7): 476-484, 1999. PMID: 10441603. DOI: 10.1056/ NEJM199908123410703

5 NCCN Clinical Practice Guidelines in Oncology (NCCN Guidelines ${ }^{\circledR}$ ). Non-Small Cell Lung. Cancer. Version 3.2020. Available at: https://www2.tri-kobe.org/nccn/guideline/lung/ english/non_small.pdf [Last accessed on April 5 ${ }^{\text {th }}, 2020$ ]

6 NCCN Clinical Practice Guidelines in Oncology (NCCN Guidelines ${ }^{\circledR}$ ). Small Cell Lung. Cancer. Version 2.2018. Available at: https://www2.tri-kobe.org/nccn/guideline/lung/ english/small.pdf [Last accessed on April $5^{\text {th }}, 2020$ ]

7 Andrews DW, Scott CB, Sperduto PW, Flanders AE, Gaspar LE, Schell MC, Werner-Wasik M, Demas W, Ryu J, Bahary JP, Souhami L, Rotman M, Mehta MP and Curran WJ Jr: Whole brain radiation therapy with or without stereotactic radiosurgery boost for patients with one to three brain metastases: phase III results of the RTOG 9508 randomised trial. Lancet 363(9422): 1665-1672, 2004. PMID: 15158627. DOI: 10.1016/S01406736(04)16250-8

8 Aoyama H, Shirato H, Tago M, Nakagawa K, Toyoda T, Hatano K, Kenjyo M, Oya N, Hirota S, Shioura H, Kunieda E, Inomata T, Hayakawa K, Katoh N and Kobashi G: Stereotactic radiosurgery plus whole-brain radiation therapy $v s$. stereotactic radiosurgery alone for treatment of brain metastases: a randomized controlled trial. JAMA 295(21): 2483-2491, 2006. PMID: 16757720. DOI: 10.1001/jama.295.21.2483

9 Chang EL, Wefel JS, Hess KR, Allen PK, Lang FF, Kornguth DG, Arbuckle RB, Swint JM, Shiu AS, Maor MH and Meyers CA: Neurocognition in patients with brain metastases treated with radiosurgery or radiosurgery plus whole-brain irradiation: a randomised controlled trial. Lancet Oncol 10(11): 1037-1044, 2009. PMID: 19801201. DOI: 10.1016/S1470-2045(09)70263-3

10 Gaspar L, Scott C, Rotman M, Asbell S, Phillips T, Wasserman $\mathrm{T}, \mathrm{McKenna}$ WG and Byhardt R: Recursive partitioning analysis (RPA) of prognostic factors in three Radiation Therapy Oncology Group (RTOG) brain metastases trials. Int J Radiat Oncol Biol Phys 37(4): 745-751, 1997. PMID: 9128946. DOI: 10.1016/s0360-3016(96)00619-0 
11 Sperduto PW, Kased N, Roberge D, Xu Z, Shanley R, Luo X, Sneed PK, Chao ST, Weil RJ, Suh J, Bhatt A, Jensen AW, Brown PD, Shih HA, Kirkpatrick J, Gaspar LE, Fiveash JB, Chiang V, Knisely JP, Sperduto CM, Lin N and Mehta M: Summary report on the graded prognostic assessment: an accurate and facile diagnosis-specific tool to estimate survival for patients with brain metastases. J Clin Oncol 30(4): 419-425, 2012. PMID: 22203767. DOI: $10.1200 /$ JCO.2011.38.0527

12 Sperduto PW, Yang TJ, Beal K, Pan H, Brown PD, Bangdiwala A, Shanley R, Yeh N, Gaspar LE, Braunstein S, Sneed P, Boyle J, Kirkpatrick JP, Mak KS, Shih HA, Engelman A, Roberge D, Arvold ND, Alexander B, Awad MM, Contessa J, Chiang V, Hardie J, Ma D, Lou E, Sperduto W and Mehta MP: Estimating survival in patients with lung cancer and brain metastases: An update of the graded prognostic assessment for lung cancer using molecular markers (Lung-molGPA). JAMA Oncol 3(6): 827 831, 2017. PMID: 27892978. DOI: 10.1001/jamaoncol. 2016.3834

13 Robinet G, Thomas P, Breton JL, Léna H, Gouva S, Dabouis G, Bennouna J, Souquet PJ, Balmes P, Thiberville L, Fournel P, Quoix E, Riou R, Rebattu P, Pérol M, Paillotin D and Mornex F: Results of a phase III study of early versus delayed whole brain radiotherapy with concurrent cisplatin and vinorelbine combination in inoperable brain metastasis of non-small-cell lung cancer: Groupe Français de Pneumo-Cancérologie (GFPC) Protocol 95-1. Ann Oncol 12(1): 59-67, 2001. PMID: 11249050. DOI: $10.1023 / \mathrm{a}: 1008338312647$

14 Lee DH, Han JY, Kim HT, Yoon SJ, Pyo HR, Cho KH, Shin SH, Yoo H, Lee SH and Lee JS: Primary chemotherapy for newly diagnosed nonsmall cell lung cancer patients with synchronous brain metastases compared with whole-brain radiotherapy administered first: result of a randomized pilot study. Cancer 113(1): 143-149, 2008. PMID: 18459180. DOI: 10.1002/ cncr.23526

15 Ali A, Goffin JR, Arnold A and Ellis PM: Survival of patients with non-small-cell lung cancer after a diagnosis of brain metastases. Curr Oncol 20(4): e300-e306, 2013. PMID: 23904768. DOI: $10.3747 /$ co.20.1481

16 Gaspar LE, Mehta MP, Patchell RA, Burri SH, Robinson PD, Morris RE, Ammirati M, Andrews DW, Asher AL, Cobbs CS, Kondziolka D, Linskey ME, Loeffler JS, McDermott M, Mikkelsen T, Olson JJ, Paleologos NA, Ryken TC and Kalkanis $\mathrm{SN}$ : The role of whole brain radiation therapy in the management of newly diagnosed brain metastases: a systematic review and evidence-based clinical practice guideline. J Neurooncol 96(1): 17-32, 2010. PMID: 19960231. DOI: $10.1007 / \mathrm{s} 11060-009-0060-9$

17 Loganadane G, Hendriks L, Le Péchoux C and Levy A: The current role of whole brain radiation therapy in non-small cell lung cancer patients. J Thorac Oncol 12(10): 1467-1477, 2017. PMID: 28733269. DOI: 10.1016/j.jtho.2017.07.006
18 Mulvenna P, Nankivell M, Barton R, Faivre-Finn C, Wilson P, McColl E, Moore B, Brisbane I, Ardron D, Holt T, Morgan S, Lee C, Waite K, Bayman N, Pugh C, Sydes B, Stephens R, Parmar MK and Langley RE: Dexamethasone and supportive care with or without whole brain radiotherapy in treating patients with non-small cell lung cancer with brain metastases unsuitable for resection or stereotactic radiotherapy (QUARTZ): results from a phase 3, non-inferiority, randomised trial. Lancet 388(10055): 2004-2014, 2016. PMID: 27604504. DOI: 10.1016/S0140-6736(16)30825-X

19 Chatani M, Matayoshi Y, Masaki N and Inoue T: Radiation therapy for brain metastases from lung carcinoma. Prospective randomized trial according to the level of lactate dehydrogenase. Strahlenther Onkol 170(3): 155-161, 1994. PMID: 8160096.

20 Murray KJ, Scott C, Greenberg HM, Emami B, Seider M, Vora NL, Olson C, Whitton A, Movsas B and Curran W: A randomized phase III study of accelerated hyperfractionation versus standard in patients with unresected brain metastases: a report of the Radiation Therapy Oncology Group (RTOG) 9104. Int J Radiat Oncol Biol Phys 39(3): 571-574, 1997. PMID: 9336134. DOI: 10.1016/s0360-3016(97)00341-6

21 Davey P, Hoegler D, Ennis M and Smith J: A phase III study of accelerated versus conventional hypofractionated whole brain irradiation in patients of good performance status with brain metastases not suitable for surgical excision. Radiother Oncol 88(2): 173-176, 2008. PMID: 18555546. DOI: 10.1016/j.radonc. 2008.05.020

22 Graham PH, Bucci J and Browne L: Randomized comparison of whole brain radiotherapy, $20 \mathrm{~Gy}$ in four daily fractions versus $40 \mathrm{~Gy}$ in 20 twice-daily fractions, for brain metastases. Int $\mathrm{J}$ Radiat Oncol Biol Phys 77(3): 648-654, 2010. PMID: 19836153. DOI: $10.1016 /$ j.ijrobp.2009.05.032

23 Zheng M, Sun H, Xu J, Yang G, Huo L, Zhang P, Tian J and Yang K: Combining Whole-Brain Radiotherapy with Gefitinib/Erlotinib for Brain Metastases from Non-Small-Cell Lung Cancer: A Meta-Analysis. BioMed Research International 2016: 1-9, 2017. DOI: 10.1155/2016/5807346

24 Arbour KC and Riely GJ: Systemic therapy for locally advanced and metastatic non-small cell lung cancer: A review. JAMA 322(8): 764-774, 2019. PMID: 31454018. DOI: 10.1001/ jama.2019.11058 